\title{
Effects and treatment applications of polymeric nanoparticles on improving platelets' storage time: a review of the literature from 2010 to 2020
}

\author{
Tahereh Zadeh Mehrizi ${ }^{1}$, Sedigheh Amini Kafiabad ${ }^{1}$, Peyman Eshghi ${ }^{2}$ \\ ${ }^{1}$ Blood Transfusion Research Center, High Institute for Research and Education in Transfusion Medicine, ${ }^{2}$ Pediatric Congenital \\ Hematologic Disorders Research Center, Shahid Beheshti University of Medical Sciences and Iran Blood Transfusion Organization, \\ Tehran, Iran
}

p-ISSN 2287-979X / e-ISSN 2288-0011 https://doi.org/10.5045/br.2021.2021094 Blood Res 2021;56:215-228.

Received on May 2, 2021

Revised on July 26, 2021

Accepted on August 25, 2021

\section{Correspondence to}

Tahereh Zadeh Mehrizi, Ph.D.

Blood Transfusion Research Center, High

Institute for Research and Education in

Transfusion Medicine, Tehran, Iran

E-mail: t.mehrizi@tmi.ac.ir

(C) 2021 Korean Society of Hematology

\begin{abstract}
Maintaining the quality of platelet products and increasing their storage time are priorities for treatment applications. The formation of platelet storage lesions that limit the storage period and preservation temperature, which can prepare a decent environment for bacterial growth, are the most important challenges that researchers are dealing with in platelet preservation. Nanotechnology is an emerging field of science that has introduced novel solutions to resolve these problems. Here, we reviewed the reported effects of polymeric nanoparticles-including chitosan, dendrimers, polyethylene glycol (PEG), and liposome- - on platelets in articles from 2010 to 2020 . As a result, we concluded that the presence of dendrimer nanoparticles with a smaller size, negative charge, low molecular weight, and low concentration along with PEGylation can increase the stability and survival of platelets during storage. In addition, PEGylation of platelets can also be a promising approach to improve the quality of platelet bags during storage.
\end{abstract}

Key Words Platelet storage lesion, Platelet storage time, PEGylation, Dendrimer, Chitosan

\section{INTRODUCTION}

Over the past three decades, platelet-rich plasma (PRP) has been used for surgeries, sports-related injuries, patients on chemotherapy and radiotherapy, children with acute lymphoblastic leukemia, patients with chronic renal failure, and many situations in which individuals suffer from dysfunctional or insufficient platelets [1]. Platelets (Fig. 1) are very small discoid-shaped cells of 1-2 $\mu \mathrm{m}$ in diameter, which circulate in the bloodstream along with other blood cells. These anucleate cells principally participate in hemostasis and plugging holes to prevent bleeding in blood vessel walls $[2,3]$. Platelet storage lesion (PSL), a complex biological event that combines collection and storage conditions, limits the shelf time of platelet bags between 3 and 7 days at $22-24^{\circ} \mathrm{C}$ in many countries. Indeed, an extended storage period may increase the risk of bacterial transmission to patients due to the optimal storage conditions for bacterial growth, loss of platelet structure, and function in vitro, which

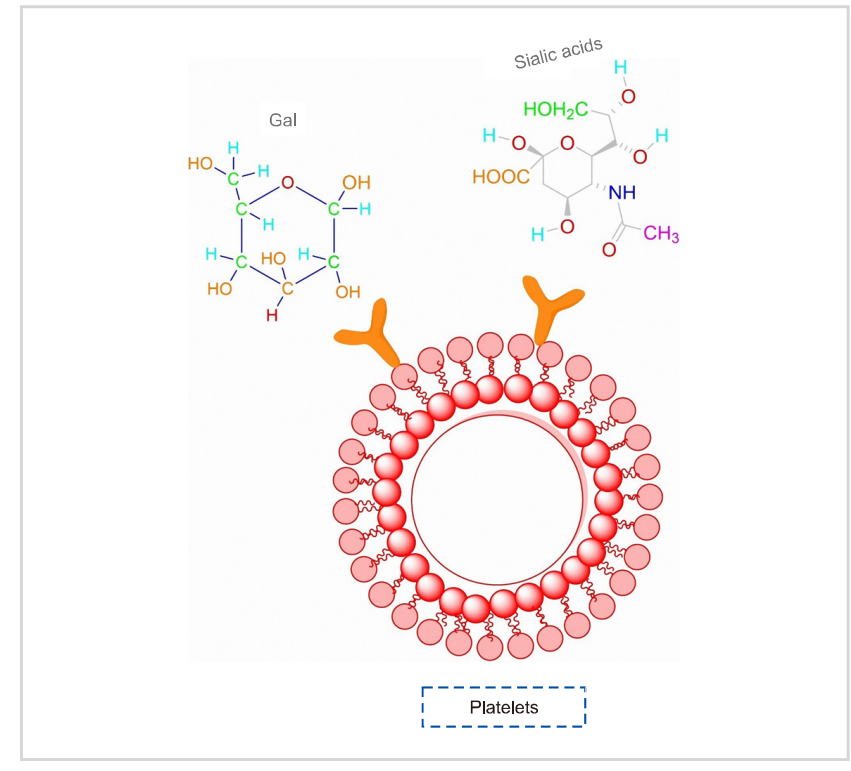

Fig. 1. Molecular structure of a platelet. 
leads to a decrease in the efficient function of platelets in patients $[2,4,5]$. Various applications of platelet production, increasing demand, limited available sources, and short shelf time of these small cells have necessitated the development of novel and efficient approaches to conserve their quality and extend the storage time.

Recently, nanotechnology has been widely used in various fields such as biology, industry, and medicine, but the safety of different nanoparticles (NPs) is still a point of conflict [6-9]. Researchers have studied the effects of different nanoparticles on the blood cells. Some nanoparticles, such as carbon and gold nanoparticles, affect platelet aggregation and lead to vascular thrombosis. However, polymeric nanoparticles, owing to their biocompatibility, as well as the high bonding capacity of the functional groups and surface modification, have been able to show higher platelet compatibility in some areas [10]. Polymeric nanoparticles are a group of nanoparticles that can be synthesized from natural, synthetic, biodegradable, or non-biodegradable polymers of nanometer size. Owing to the possibility of high surface modification in these nanoparticles, they are used to reduce the side effects during drug delivery and increase the biocompatibility of nanoparticles for various applications. These nanoparticles are usually biodegradable and classified into two classes based on their properties: i) agro-polymers (e.g., polysaccharides and proteins) and ii) biopolystyrenes (e.g., microorganisms and synthetic polymers). Biodegradable synthetic nanopolymers are also divided into two groups: i) synthetic [e.g., polylactic acid (PLA), poly(lactic-co-glycolic acid) (PLGA), polyanhydride, polycaprolactone (PCL), and poly(alkyl cyanoacrylate) (PACA)] and ii) natural (e.g., alginate, chitosan, cellulose gelatin, pullulan). However, there are also non-biodegradable types of synthetic nanopolymers, such as poly(methyl acrylate) (PMA) and polyamidoamine (PAMAM) [11].

In this regard, in the present study, we investigated the recent findings on the effects of different polymeric nanoparticles, namely chitosan, dendrimers, polyethylene glycol, and liposomes, on the structure and function of platelets, on platelet function.

\section{RESULTS}

\section{Chitosan (CS)}

Chitosan (Fig. 2) is obtained from the partial deacetylation of chitin and is composed of acetylated units of N-acetyl-D-glucosamine and deacetylated units of $\beta-(1 \rightarrow 4)$-linked $\mathrm{D}$-glucosamine. This nanopolymer is a cationic natural biodegradable polysaccharide that possesses properties such as biocompatibility and antimicrobial activity with low immunogenicity [12-17]. Owing to the positive surface charge, these nanoparticles can often react with negatively charged surfaces in blood, such as cell membranes and amino acids in serum proteins [18]. Naturally, platelets as blood cells can be affected by these nanoparticles depending on the properties of the polymer, such as composition, mobility, charge density, and the degree of hydrophilicity/ hydrophobicity. The interaction between positively charged chitosan and platelets, which leads to an increase in platelet adhesion and activation, has been widely used in wound dressing [19-23]. Gu et al. [24] introduced a fly larva shell-derived chitosan sponge (CS) and evaluated its feasibility for internal use as an absorbable surgical hemostatic agent in a rat model of hepatic hemorrhage. They reported that CS is a better implantable hemostatic material than gelatin sponge (GS) or oxidized cellulose (OC) in both acute and chronic bleeding models, which is related to the greater ability of CS to enhance platelet activation, erythrocyte aggregation, morphological alteration, and thrombin generation at sites in which it is applied.

Wang et al. [18] investigated the relative efficacies of chitosan-based and conventional gauze dressings in a rat model of femoral artery hemorrhage and patients with surgical wounds and evaluated the dressing effectiveness based on hemostatic profiles, biocompatibility, antimicrobial activity, and blood factor responses in coagulation. They reported that chitosan fiber (CF) dressing treatment significantly shortened the time to hemostasis in injured rats. Moreover, the CF dressing significantly prolonged partial thromboplastin time, enhanced blood absorption, and reduced antithrombin production without altering the prothrombin ratio. Unlike regular gauze bandages, CF dressing demonstrated remarkable antibacterial activity. The results of this study indicate the effectiveness of chitosan as a hemostatic dressing and elucidate its underlying mechanism.

In addition, He et al. [25] synthesized CS films with varying degrees of protonation, and then used these films to evaluate the influence of the positive charge of CS on the coagulation system. Based on their study, a positive charge on the CS surface could increase platelet activation and adhesion and accelerate fibrinogen adsorption. However, it inhibited the

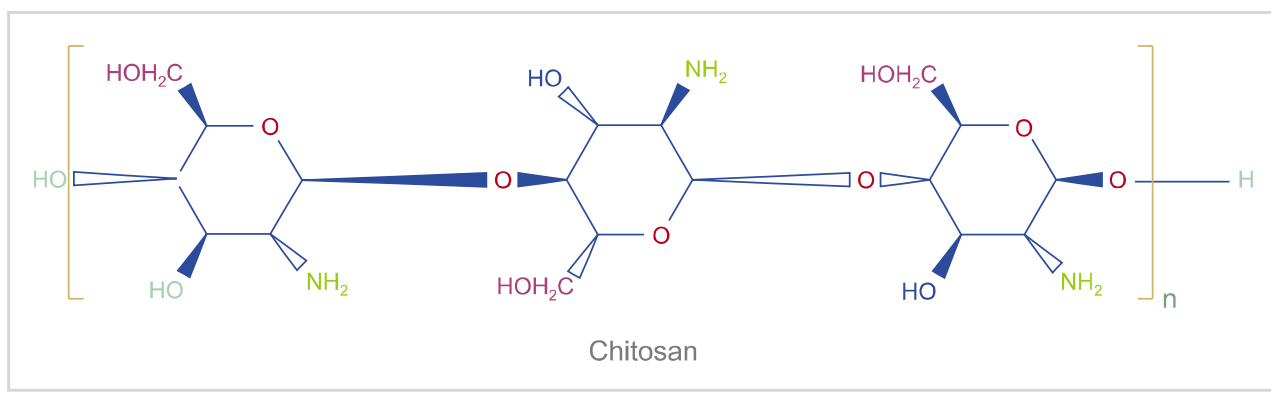

Fig. 2. Chemical structure of chitosan. 
contact system, thereby slowing down the formation of thrombin and clots.

The contact system is the effect of polymers on blood systems after the absorption of proteins, which can alter the function of proteins and related systems such as coagulation and inflammation [20]. By investigating the impact of the contact system on the interaction of positively charged CS and platelets, Lord et al. [26] suggested that the positive surface charge of chitosan can induce platelet aggregation, but this effect is enhanced in the presence of the contact system and after protein adsorption on the NPs. In addition, p-selectin expression showed that fibrinogen- and perlecan-coated CS NPs increased platelet activation more than fibrinogen and perlecan alone. However, platelet activation was the same in collagen-coated CS NPs, collagen, and CS.

In another study, Chung et al. [27] coated CS NPs with adenosine diphosphate (ADP) and fibrinogen to improve platelet activation and then determined their hemostatic effects. They assumed that these NPs could enhance platelet activation because fibrinogen could improve platelet activation by attaching to the glycoprotein IIb/IIIa receptor on platelets. In addition, ADP, as a platelet activator, induces platelet activation through ADP receptors such as P2Y1, $\mathrm{P} 2 \mathrm{Y} 12$, and P2X1. ADP-coated CS could increase platelet aggregation and bind to the RBC membrane, while fibrinogen-coated CS could be inserted into the fibrin network of clots. As a result, all NPs, especially ADP-coated CS, shortened the coagulation time and altered the mechanical structure of the clot.

Periayah et al. [28] described the impact of different CS formulations on platelets. Based on their study, molecular weights and degree of deacetylation could affect platelets differently. They also showed that clotting and release of platelets involved in hemostasis were induced by oligo-chitosan 53 and oligo-chitosan 52.

Jesus et al. [29] compared different CS NPs with respect to the molecular weight (MW) or deacetylation degree (DDA) of CS. They revealed that only chitosan with 93\% deacetylation could cause platelet aggregation.

Thus far, the encapsulation of some thrombotic compounds has increased their properties. In this context, ellagic acid

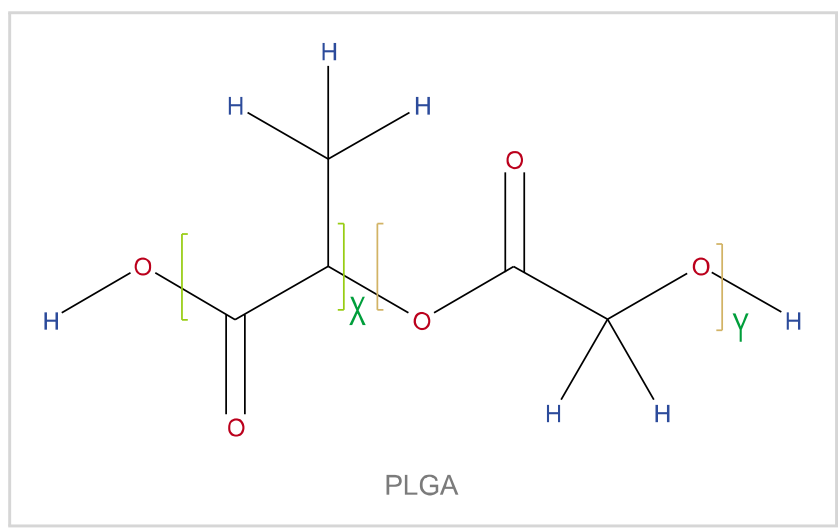

Fig. 3. Chemical structure of PLGA. was encapsulated in CS-NPs by Gopalakrishnan et al. [30]. According to their study, encapsulation of ellagic acid into CS increased thrombotic activity and decreased clotting and retraction times more than ellagic acid.

In a study conducted by Ramtoola et al. [31], the effects of CS, PLGA (Fig. 3), and PLGA-macrogol NPs in micro-and nanometer-sized platelets were examined. They investigated the roles of size (micro-and nanometer) and surface morphology (smooth, spherical, and irregular) of the NPs in platelets. They showed that these nanoparticles had neither an inductive nor an inhibitory effect on platelet aggregation.

In addition, the positive surface charge of chitosan can be reduced in various ways, and new properties can be created in this NP using this approach. In this regard, Shelma and Sharma [32] synthesized lauroyl sulfated chitosan (LSCS) NPs, which are amphiphilic derivatives of CS, and then assessed their effects on hemocompatibility. They described that this CS derivative was more blood-compatible than CS. They inhibited the hemolytic activity of CS on RBCs and stopped morphological changes and aggregation in platelets. As a result, the clotting time increased when using this derivative compared to CS.

Furthermore, Xiong et al. [33] prepared water-soluble derivatives of CS (WSC) and determined their blood compatibilities. Based on their study, N,O-succinyl chitosan (NOSCS) and N-succinyl chitosan (NSCS) had more anticoagulant activity and were more blood compatible than CS. The activated partial thromboplastin time (aPTT) and thrombin time (TT) were increased by both WSCs but had no effect on prothrombin time (PT) and clotting inhibition.

In 2011, Jiang et al. [34] studied chitosan modified with salicylic acid. They prepared an amphiphilic chitosan derivative that possessed both antiplatelet aggregation and antiplatelet adhesion properties. The in vitro results showed that the platelet aggregation inhibitory activity of different agonists was dose-dependent. Indeed, the antiplatelet aggregation capability of SA-CS at low concentrations was remarkably better than that of low-dose aspirin. The platelet adhesion test showed a significant difference between the effect of SA-CS and that of the control group. These results indicate that SA-chitosan can be potentially used as an antiplatelet aggregation and adhesion agent.

In addition, Kim et al. [35] investigated the antithrombotic activities of nanoencapsulation of red ginseng extract using chitosan with 4 polyglutamic acid or fucoidan. Both in vitro rabbit and ex vivo rat platelet aggregation of RG loaded chitosan was significantly $(P<0.05)$ decreased within P-NPs and F-NPs.

Table 1 represents the results in detail.

\section{Dendrimers}

Dendrimers are 3D-hyperbranched, monodisperse, and nanosized structures, which are composed of a symmetric core, branched functional groups, and internal cavities [36]. These molecules can form multiple bonds with different drugs and compounds through functional groups or encapsulate them through their inner cavities [37, 38]. Dendrimers 
Table 1. The effects of different polymeric nanoparticles on platelets.

\begin{tabular}{|c|c|c|c|c|c|c|}
\hline NPs & Type and coating & $\begin{array}{l}\text { Size } \\
(\mathrm{nm})\end{array}$ & Charge & $\begin{array}{l}\text { Induction of platelet } \\
\text { aggregation }\end{array}$ & $\begin{array}{l}\text { Other effects on } \\
\text { platelets }\end{array}$ & Ref. \\
\hline \multirow[t]{17}{*}{ CS } & $\begin{array}{l}\text { Fly-larva shell-derived chitosan } \\
\text { sponge (CS) }\end{array}$ & & & Induced & Hemostatic material & [24] \\
\hline & CS & & + & & $\begin{array}{l}\text { Induced RBC and } \\
\text { platelet adhesion, } \\
\text { fibrinogen } \\
\text { adsorption, and } \\
\text { platelet activation, } \\
\text { and retarded } \\
\text { thrombin formation } \\
\text { and clotting }\end{array}$ & [25] \\
\hline & $\begin{array}{l}\text { Fibrinogen- and perlecan-coated CS } \\
\text { NPs }\end{array}$ & & & Induced & $\begin{array}{l}\text { The ability of platelet } \\
\text { activation more than } \\
\text { each one of } \\
\text { fibrinogen and } \\
\text { perlecan }\end{array}$ & [26] \\
\hline & Collagen-coated CS NPs & & & Induced & $\begin{array}{l}\text { Activation of platelets } \\
\text { similar to either } \\
\text { chitosan or collagen }\end{array}$ & [26] \\
\hline & ADP-decorated CS (ANPs) & $251.0 \pm 9.8$ & + & Induced & Shorten clotting times & [27] \\
\hline & Fibrinogen-decorated CS (FNPs) & $326.5 \pm 14.5$ & + & & Shorten clotting times & [27] \\
\hline & $\begin{array}{l}\text { N, O-carboxymethylchitosan } \\
\text { (NO-CMC), O-carboxymethylchitosan } \\
\text { (O-CMC) and Oligo-chitosan (O-C) }\end{array}$ & & & $\begin{array}{l}\text { Induced by O-C } 53 \\
\text { and O-C } 52\end{array}$ & $\begin{array}{l}\text { O-C } 53 \text { and O-C } 52 \\
\text { caused platelets } \\
\text { release }\end{array}$ & [28] \\
\hline & CS 93\% DDA NPs & $292 \pm 52$ & + & Induced & $\begin{array}{l}\text { Induced CS-platelet } \\
\text { interaction }\end{array}$ & [29] \\
\hline & Ellagic acid encapsulated CS-NPs & 80 & & & $\begin{array}{l}\text { Anti-hemorrhagic } \\
\text { effect }\end{array}$ & [30] \\
\hline & PLGA & 209 & - & Inert & & [31] \\
\hline & PLGA-macrogol & 138 & - & & & \\
\hline & Chitosan $(2.5 \% \mathrm{w} / \mathrm{v})$-coated PLGA & 343 & + & & & \\
\hline & Chitosan (15\% w/v)-coated PLGA & 443 & $\begin{array}{l}+ \\
+\end{array}$ & & & \\
\hline & Lauroyl sulfated chitosan (LSCS) & 886 & - & Inert & & [32] \\
\hline & $\begin{array}{l}\text { N, O-succinyl chitosan (NOSCS) and } \\
\text { N-succinyl chitosan (NSCS) }\end{array}$ & & - & & Increased APTT and TT & [33] \\
\hline & Salicylic acid SA-CS-NPs & $292 \pm 2$ & + & Inhibited & $\begin{array}{l}\text { Anti-platelet and } \\
\text { anti-adhesion } \\
\text { properties }\end{array}$ & [34] \\
\hline & $\begin{array}{l}\text { Polyglutamic acid (PGA) and fucoidan } \\
\text { (Fu)-ginseng extract-loaded } \\
\text { chitosan (CS) }\end{array}$ & & & Inhibited & $\begin{array}{l}\text { Antithrombotic and } \\
\text { antiplatelet effects }\end{array}$ & [35] \\
\hline \multirow[t]{5}{*}{ Dendrimers } & PAMAM & G3-G6 & +/Neu/- & $\begin{array}{l}\text { Induced by cationic } \\
\text { Inert by anionic and } \\
\text { neutral }\end{array}$ & $\begin{array}{l}\text { Only large cationic } \\
\text { dendrimers could } \\
\text { induce platelet } \\
\text { aggregation. They } \\
\text { disrupted platelet } \\
\text { membrane integrity }\end{array}$ & {$[39,40]$} \\
\hline & NH2-PAMAM & Different & + & Induced & $\begin{array}{l}\text { Cationic dendrimers } \\
\text { induced DIC-like } \\
\text { complications }\end{array}$ & [41] \\
\hline & NH2-PAMAM & G7 & + & Induced & $\begin{array}{l}\text { Alternation in platelet } \\
\text { shape and activation }\end{array}$ & {$[42,43]$} \\
\hline & NH2-PAMAM & & + & $\begin{array}{l}\text { Dose-dependently } \\
\text { Inhibited }\end{array}$ & $\begin{array}{l}\text { Decreased platelet } \\
\text { aggregation at high } \\
\text { doses }\end{array}$ & [44] \\
\hline & $\begin{array}{l}\text { Hydroxylated-PAMAM } \\
\text { Carboxylated-PAMAM }\end{array}$ & & $\begin{array}{c}\text { Neutral } \\
-\end{array}$ & Inert & Blood compatible & [44] \\
\hline
\end{tabular}


Table 1. Continued 1.

\begin{tabular}{|c|c|c|c|c|c|c|}
\hline NPs & Type and coating & $\begin{array}{l}\text { Size } \\
(\mathrm{nm})\end{array}$ & Charge & $\begin{array}{l}\text { Induction of platelet } \\
\text { aggregation }\end{array}$ & $\begin{array}{l}\text { Other effects on } \\
\text { platelets }\end{array}$ & Ref. \\
\hline \multirow[t]{27}{*}{ Dendrimers } & PAMAM & G3 and G6 & $\begin{array}{l}+ \\
-\end{array}$ & $\begin{array}{l}\text { Induced } \\
\text { Inhibited }\end{array}$ & $\begin{array}{l}\text { Platelet aggregation } \\
\text { depended on } \\
\text { generation, surface } \\
\text { charge, and } \\
\text { concentration of the } \\
\text { dendrimers }\end{array}$ & [45] \\
\hline & PAMAM & G1-G3 & + & Induced & Cationic: prolonged & [46] \\
\hline & & G1.5-G3.5 & - & Inhibited & $\begin{array}{l}\text { PT, inhibited } \\
\text { thrombin, and } \\
\text { changed fibrinogen } \\
\text { coagulability } \\
\text { Anionic: inert }\end{array}$ & \\
\hline & G3-Triazine & G3, G5 & + & Induced & Triazine is more & [47] \\
\hline & G3-PAMAM & and G7 & & & platelet compatible & \\
\hline & G5-Triazine & & & & than PAMAM & \\
\hline & G6-PAMAM & & & & & \\
\hline & G7-Triazine & & & & & \\
\hline & NH2-PAMAM & $\begin{array}{l}\mathrm{G} 2, \mathrm{G} 3 \\
\text { and G4 }\end{array}$ & + & Induced & $\begin{array}{l}\text { Platelet aggregation } \\
\text { depending on size } \\
\text { and molecular } \\
\text { weight }\end{array}$ & [48] \\
\hline & NH2-PAMAM & G3-G5 & + & Negligibly induced & Cationic: changes in & [49] \\
\hline & OH-PAMAM & G5 & $\mathrm{Neu}$ & Inert & RBC shape & \\
\hline & & & & & $\begin{array}{l}\text { Cationic and neutral: } \\
\text { structurally altered } \\
\text { fibrinogen }\end{array}$ & \\
\hline & PEG- thiolated G4 PAMAM & G4 & $\begin{array}{l}\text { Decreased } \\
\text { positive } \\
\text { surface charge }\end{array}$ & $\begin{array}{l}\text { Decreased platelet } \\
\text { aggregation of } \\
\text { PAMAM }\end{array}$ & $\begin{array}{l}\text { Increased PT, and } \\
\text { activated PTT }\end{array}$ & [50] \\
\hline & PAMAM-Titanium oxide ( $\mathrm{TiO} 2$ ) films & G1-G4 & + & Inhibited & $\begin{array}{l}\text { Inhibited platelet } \\
\text { adhesion and } \\
\text { activation }\end{array}$ & [52] \\
\hline & CGS21680-PAMAM & G3 & + & $\begin{array}{l}\text { Inhibited } \\
\text { ADP-induced platelet } \\
\text { aggregation }\end{array}$ & & [54] \\
\hline & MSR 2500-PAMAM & G3 & + & $\begin{array}{l}\text { Inhibited } \\
\text { ADP-induced platelet } \\
\text { aggregation }\end{array}$ & & [55] \\
\hline & (Mal-III) coated G4 PPI & G4 & & Negligibly induced & $\begin{array}{l}\text { Increased blood } \\
\text { compatibility of } \\
\text { unmodified PPI }\end{array}$ & [56] \\
\hline & (Mal-III) coated G4 PPI & G4 & & & $\begin{array}{l}\text { In vivo: reduced } \\
\text { platelet count in a } \\
\text { concentration-depen } \\
\text { dent manner }\end{array}$ & [57] \\
\hline & PPI-G4-OS-Mal-III & G4 & & & $\begin{array}{l}\text { Selectively toxic } \\
\text { against CLL cells and } \\
\text { blood compatible }\end{array}$ & [58] \\
\hline & PPI-G4-DS-Mal-III & G4 & & Inert & $\begin{array}{l}\text { More blood } \\
\text { compatible than } \\
\text { unmodified PPI }\end{array}$ & [59] \\
\hline & Carbosilane dendronized gold NPs & G1 & + & Induced & Blood compatible & [60] \\
\hline & Carbosilane dendronized gold NPs & G1-G3 & + & Induced by G3 & & [61] \\
\hline & Carbosilane dendrimers & G1-G3 & + & Induced & $\begin{array}{l}\text { Dose- and size- } \\
\text { dependently } \\
\text { increased platelet } \\
\text { aggregation }\end{array}$ & [62] \\
\hline & Phosphorus dendrimer & G4 & + & Inert & & [62] \\
\hline & $\begin{array}{l}\text { PEGylated carbosilane dendronized } \\
\text { gold NP }\end{array}$ & G1-G3 & + & Inhibited & $\begin{array}{l}\text { Reduced hemolysis, } \\
\text { platelet aggregation } \\
\text { and toxicity }\end{array}$ & [63] \\
\hline & ALGD & G1-G2 & & & Safe for human cells & [66] \\
\hline & PGLD-streptokinase & G5 & - & Inhibited & Inhibited CD62P & [69] \\
\hline
\end{tabular}


Table 1. Continued 2.

\begin{tabular}{|c|c|c|c|c|c|c|}
\hline NPs & Type and coating & $\begin{array}{l}\text { Size } \\
(\mathrm{nm})\end{array}$ & Charge & $\begin{array}{l}\text { Induction of platelet } \\
\text { aggregation }\end{array}$ & $\begin{array}{l}\text { Other effects on } \\
\text { platelets }\end{array}$ & Ref. \\
\hline \multirow[t]{8}{*}{ PEG } & PEGylated platelets & & & & $\begin{array}{l}\text { Improved storage } \\
\text { condition and } \\
\text { decrease storage } \\
\text { temperature }\end{array}$ & {$[72-74]$} \\
\hline & PEGylated platelets & & & & $\begin{array}{l}\text { Prevent } \\
\text { bacteria-platelet } \\
\text { interaction in blood } \\
\text { bags }\end{array}$ & {$[76]$} \\
\hline & PAMAM-PEG-CGS21680 & G3 & & $\begin{array}{l}\text { Inhibit ADP-mediated } \\
\text { platelet aggregation }\end{array}$ & $\begin{array}{l}\text { The molecular weight } \\
\text { of PEG and the } \\
\text { number of its } \\
\text { branches affected on } \\
\text { this inhibition }\end{array}$ & [77] \\
\hline & PEGylated lipid NPs could & & & $\begin{array}{l}\text { Inhibit ADP- and } \\
\text { collagen-induced } \\
\text { platelet aggregation }\end{array}$ & $\begin{array}{l}\text { Decreased P-selectin, } \\
\text { inhibit platelet } \\
\text { aggregation } \\
\text { depending to charge } \\
\text { and concentration }\end{array}$ & [78] \\
\hline & PEG-LEHs & & & & $\begin{array}{l}\text { Reduce } \\
\text { thrombocytopenic } \\
\text { reaction }\end{array}$ & [79] \\
\hline & PEG-LEHs & & & & $\begin{array}{l}\text { Inert on collagen-, } \\
\text { thrombin- and } \\
\text { ristocetin-induced } \\
\text { platelet aggregation }\end{array}$ & {$[80]$} \\
\hline & PEGylated PLGA NPs & & & Inert & $\begin{array}{l}\text { Bind and internalize } \\
\text { onto platelets }\end{array}$ & [81] \\
\hline & PEGylated PLGA NPs & $\begin{array}{l}113,321 \\
\text { and } 585\end{array}$ & & $\begin{array}{l}\text { Inert in the size of } \\
113 \mathrm{~nm} \\
\text { Inhibited ADP- } \\
\text { induced platelet } \\
\text { aggregation in the } \\
\text { sizes of } 321 \text { anf } 585\end{array}$ & Blood compatible & [82] \\
\hline \multirow[t]{6}{*}{ Liposomes } & $\begin{array}{l}\text { Ticagrelor-liposomal nanoparticles } \\
\text { bearing the tumor-homing } \\
\text { pentapeptide CREKA }\end{array}$ & & & & $\begin{array}{l}\text { Suppressed } \\
\text { tumor-associated } \\
\text { platelets }\end{array}$ & [86] \\
\hline & H12-(ADP)-vesicles & & & Induced & $\begin{array}{l}\text { In vitro: induced } \\
\text { platelet aggregation } \\
\text { In vivo: prolonged } \\
\text { bleeding time }\end{array}$ & [87] \\
\hline & Cyclic RGD-modified liposomes & & & & $\begin{array}{l}\text { Selectively targeted } \\
\text { activated platelets }\end{array}$ & [88] \\
\hline & $\begin{array}{l}\text { Liposomes encapsulating } \\
\text { streptokinase }\end{array}$ & & & & $\begin{array}{l}\text { Selectively targeted } \\
\text { activated platelets }\end{array}$ & [89] \\
\hline & $\begin{array}{l}\text { Liposomes loaded with methotrexate } \\
\text { (MTX-DOG) and melphalan } \\
\text { (Mlph-DOG) decorated with } \\
\text { tetrasaccharide }\end{array}$ & & & $\begin{array}{l}\text { Induced by } \\
\text { MTX-DOG }\end{array}$ & $\begin{array}{l}\text { MTX-DOG Induced } \\
\text { platelet aggregation, } \\
\text { C-activation, and } \\
\text { disrupted } \\
\text { coagulation }\end{array}$ & [90] \\
\hline & Encapsulated thrombin in liposomes & & & & $\begin{array}{l}\text { Platelets were more } \\
\text { sensitive to agonist } \\
\text { after uptake } \\
\text { thrombin }\end{array}$ & [91] \\
\hline
\end{tabular}

are divided into several types based on the surface charge (cationic, neutral, and anionic), generation, and type of functional groups. Dendrimers with different properties can have different effects on platelets, some of which are reviewed here. One of the most popular types of cationic dendrimers is the PAMAM dendrimer (Fig. 4). The core of this dendrimer is composed of ethylene diamine (EDA) or ammonia, and the branches contain amidoamine residues. A positive charge density is formed on the surface of the PAMAM dendrimers owing to the presence of many NH2-terminated groups. As a result, this positively charged surface can interact with the negatively charged surface of platelets and other blood 


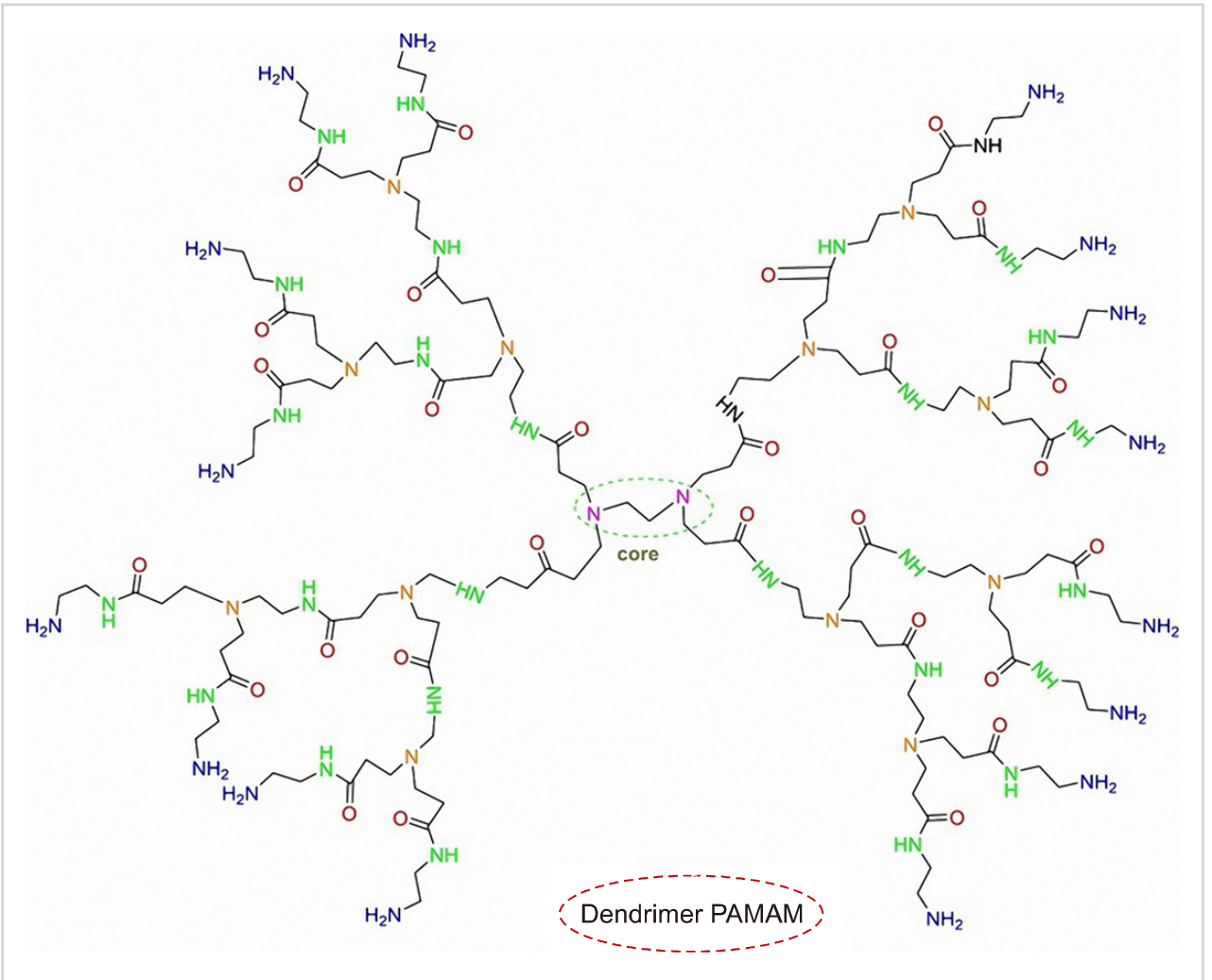

Fig. 4. Chemical structure of a PAMAM dendrimer components. Thus, they are usually not blood-compatible, without any surface modification. In two preliminary studies, Dobrovolskaia et al. $[39,40]$ synthesized 12 different PAMAM dendrimers and then investigated the roles of size and surface charge of them in their platelet compatibility. They revealed that an increase in the NH2-terminated groups on the dendrimer surface was associated with an increase in platelet aggregation. Thus, only larger cationic dendrimers could induce platelet aggregation, while anionic, neutral, and smaller PAMAM had no effect on platelets. They described that these influences were independent of membrane microparticle release and likely induced platelet activation in a different way from conventional pathways. In addition, they disrupt the membrane integrity.

The effect of surface charge on PAMAM-platelet interaction was also determined in an in vivo study conducted by Greish et al. [41]. Based on their study, coagulopathy disorders such as DIC-like complications were induced by injection and feeding of cationic dendrimers in mice, whereas anionic dendrimers did not have such effects.

The evaluation of cationic PAMAM impacts on platelets was carried out in two separate in vivo and in vitro studies by Jones et al. [42, 43]. According to their study, cationic dendrimers trigger platelet activation by inducing $\alpha$-granule release and platelet morphological changes. Moreover, they showed that cationic dendrimers could disrupt the activity of enzymes on the platelet surface and prevent the formation of prothrombinase complexes by inhibiting the binding of precoagulation proteins. Similar to a previous study by Jones et al. [42, 43], they also reported DIC-like complications mediated by cationic PAMAM and explained that these disorders were created by an interaction between dendrimers and negatively charged serum proteins (such as fibrinogen).

In addition, Chitlur et al. [44] functionalized PAMAM dendrimers with $\mathrm{NH} 2$ (cationic), $\mathrm{OH}$ (neutral), and $\mathrm{COOH}$ (anionic) at different concentrations and examined their possible effects on platelets. They examined the effect of surface charge and increasing concentration on dendrimer-platelet interactions. According to their results, anionic (carboxylated) dendrimers, even at the highest concentrations, and neutral dendrimers (hydroxylates) prevented the aggregation of platelets from the same platelet bag, while cationic dendrimers (PAMAM) caused platelet aggregation.

Additionally, Šemberová [45] assessed the influence of G3 and G6 PAMAM dendrimers as a function of generation and surface charge on the expression of CD62P marker of platelets in an in vitro study. They showed that a more negative surface charge was more effective in reducing platelet aggregation. In addition, the results of this study showed that molecular size and weight are important in inducing platelet aggregation. In addition, platelet aggregation was completely dependent on concentration, so that the low concentration caused less aggregation. Moreover, both G3 and G4 dendrimers increased CD62P in platelets, which is related to platelet activation.

In another study, Aisina et al. [46] evaluated the effects of cationic and anionic PAMAM dendrimers on platelet concentrates. Studies on platelet bags showed that although positively charged dendrimers caused platelet aggregation and deformation in plasma, anionic dendrimers did not have 
such effects. The anionic dendrimers could prevent platelet aggregation from the same platelet bags and increase the platelet survival rate. On the other hand, the results of their studies showed that increasing the size and dose of both types of dendrimers increased their effects.

In addition, Enciso et al. [47] compared the effects of PAMAM and triazine on platelets and suggested that triazine dendrimers were more platelet compatible than PAMAM and induced less platelet aggregation. Platelet aggregation mediated by triazine dendrimers increased in higher numbers.

Watala et al. [48] investigated the effects of generation on cationic PAMAM-induced platelet aggregation. According to their study, higher generation and molecular weight in PAMAM dendrimers increased the zeta potential of the surface, resulting in greater platelet activation.

In a study conducted by Fu et al. [49], the influence of PAMAM on platelets was determined as a function of generation (G3-G5), surface residues (NH2-G5 and $\mathrm{OH}-\mathrm{G} 5$ ), and dose. They reported that all cationic dendrimers in their study could negligibly induce platelet aggregation; however, they dose- and generation-dependently cause hemolysis and RBC morphological alterations. At higher concentrations, cationic PAMAM inhibited the coagulation factors. Although both NH2- and $\mathrm{OH}$-terminated dendrimers induced conformational changes in fibrinogens, only NH2-terminated PAMAM could impair fibrinogen polymerization.

However, these cationic dendrimers can be modified by coating agents to synthesize anionic and neutral forms with less cytotoxic effects.

In another study conducted by Liu et al. [50], both PEGylation and thiolation were applied to inhibit PAMAMinduced platelet aggregation. The results revealed that thiolated-PAMAM reduced platelet aggregation. However, PEGylation of thiolated-PAMAM significantly inhibited PAMAM-mediated platelet aggregation.

In addition, Alavi et al. [51] coated PEG-cyclic RGD to PAMAM and revealed that PEG-cyclic RGD-PAMAM reduced PAMAM-induced hemolysis and platelet aggregation.

In another study, Li et al. [52] coated titanium oxide ( $\mathrm{TiO} 2)$ films with G1-G4 PAMAM dendrimers and determined their possible impact on platelet adhesion and activation in platelet-rich plasma (PRP). They showed that the stabilization of PAMAM on titanium oxide films could inhibit platelet adhesion and activation.

Some studies have also inhibited ADP-mediated platelet aggregation by binding adenosine receptor antagonists to dendrimers [53].

Kim et al. [54] attached CGS21680 (A2AAR receptor antagonist) and de Castro et al. [55] attached MSR 2500 (P2Y1 receptor antagonist) to PAMAM. Both studies revealed that the binding of adenosine receptor antagonists to PAMAM could inhibit ADP-induced platelet aggregation [54, 55].

Another important cationic dendrimer in the field of drug delivery is polypropylene imine (PPI). The central core of PPI is composed of EDA and diaminobutane (DAB), and its internal structure contains alkyl and tertiary amine residues. Similar to PAMAM, PPI also has a positive surface charge and can interact with negatively charged components and cells in the blood. To reduce the cytotoxicity of these positively charged dendrimers, surface modification studies have been conducted.

Ziemba et al. [56, 57] used maltotriose to mask the positive surface charge of G4 PPI and then determined its effect on blood components in an in vivo study. They compared the blood compatibility of unmodified PPI with PPI modified by $25 \%$ and $100 \%$ maltotriose and showed that surface modification could reduce platelet aggregation in cationic PPI [56].

To selectively deliver the drug to chronic lymphocytic leukemia (CLL) cells, Franiak-Pietryga et al. $[58,59]$ synthesized a maltotriose-coated PPI dendrimer (PPI-G4-OS-MalIII) that was not harmful to blood cells. Modified PPIs reduced PPI-induced platelet aggregation and did not cause platelet aggregation, even at higher doses.

Cationic carbosilane dendrons are cationic dendrimers that can affect platelets. In this regard, the blood compatibility of gold nanoparticles stabilized with carbosilane dendrons was determined by Peña-González et al. [60]. Based on their results, carbosilane dendrons could induce platelet aggregation and hemolysis in a generation-dependent manner, such that higher generation induced higher platelet aggregation. Moreover, G1 dendronized gold NPs were RBC compatible; however, they induced platelet aggregation.

In the study by Pedziwiatr-Werbicka et al. [61], the effects of gold nanoparticles stabilized with carbosilane dendrons were determined on platelets as a function of dendron generation. They showed that although G1 and G2 had no effect on platelets, G3 increased platelet aggregation.

In addition, the influence of cationic carbosilane phosphorus-containing dendrimers and their complexes with siRNA and oligodeoxynucleotides (ODN) was examined on platelets by Dzmitruk et al. [62]. They showed that dendrimers could induce platelet aggregation in a dose- and generation-dependent manner. The binding of dendrimers to nucleic acids reduces their platelet aggregatory ability.

In the field of surface modification, Barrios-Gumiel et al. [63] investigated the influence of PEGylation on the hemocompatibility of gold NPs stabilized by carbosilane dendrons. According to their study, PEGylation reduced hemolytic activity and platelet-agglomeration of dendronized gold NPs, which depended on dendron generation and dendron/PEG.

In addition to cationic dendrimers, anionic types are usually more blood compatible. Anionic linear globular dendrimers (ALGDs) are anionic dendrimers with low toxicity, high biocompatibility, biodegradability, and water-solubility [64-66]. They are synthesized using cost-effective methods and have a low dispersion index. Structurally, their core is PEG, and their outer branches have carboxyl groups. The negative charge of ALGD reduces repulsive forces and cell binding, thereby decreasing the interaction between loaded drugs and receptors. As a result, the viability of cells improves because they can easily remove deleterious components. The cellular mechanism of ALGD uptake is not clear, but dendrimers usually enter cells via receptor-mediated internal- 
ization [66].

Mehrizi et al. [66] prepared an ALGD using PEG (core) and citric acid (branches). These NPs were soluble in water and could not induce cytotoxic effects on human cells.

Mirzaei et al. [67] linked ALGD to the antibody and showed that the nanoparticles were capable of binding to the protein and reducing the toxicity of the antibody. They PEGylated erythropoietin analogs using ALGDs and investigated their properties in vitro. Despite these extraordinary properties, no studies have yet determined the effects of ALGD nanoparticles on platelets.

However, they were not able to induce hemolysis in the study by Alavidjeh et al. [68], indicating their proper blood compatibility.

Another anionic dendrimer is the polyglycerol dendrimer (PGLD), which was used in the study by Fernandes et al. [69] to coat microtiter plates in order to compare the change in platelet adhesion to this surface with the unchanged polystyrene surface. They showed that G5 PGLD-streptokinase was an antithrombogenic agent that could decrease platelet adhesion based on CD62P expression. The data are presented in Table 1.

\section{Polyethylene glycol (PEG)}

These synthetic, hydrophilic, and biocompatible nanopolymers (Fig. 5) are composed of petroleum [70, 71]. PEGylation has received considerable attention in the field of platelet storage. According to previous studies, PEGylation can reduce the storage temperature of platelets to $4^{\circ} \mathrm{C}$ and even sub-zero temperatures without inducing any changes in platelet structure and viability. In addition, PEGylated platelets have also been used to prevent bacteria from reacting with platelets in platelet bags and to increase transfusion safety [72].

In this context, a methoxy-PEGylation (mPEG) approach was applied by Scott et al. [72] to reduce the temperature storage and PSL in mPEGylated platelets in an in vitro study. They showed that PEGylation of platelet membranes could reduce the PSLs in platelets. In this study, PEG as a cryoprotectant allowed platelets to be stored at $4^{\circ} \mathrm{C}$ or even frozen at $-20^{\circ} \mathrm{C}$ so that platelet count, morphology, and function remained normal during storage. PEG can react with

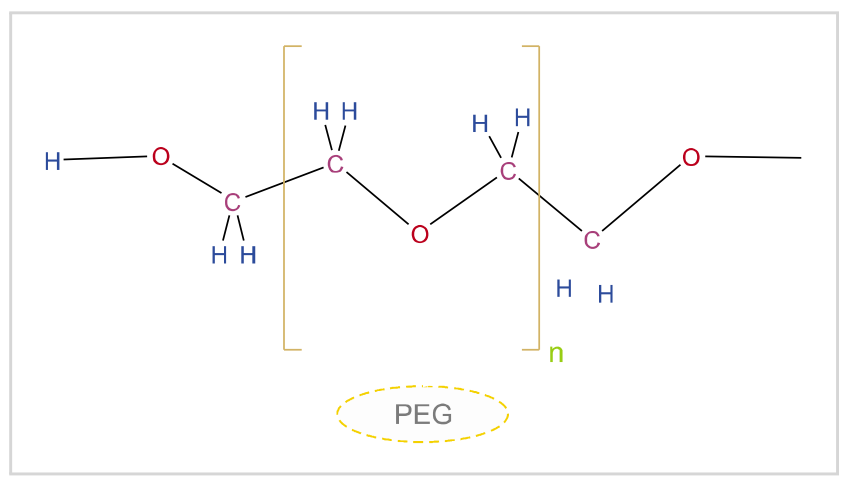

Fig. 5. Chemical structure of PEG. lysine residues in the surface proteins of platelets and bind them by forming a stable amide bond. This bond prevents the platelet surface glycoproteins from changing their shape and sticking together during storage. In addition, they showed that among PEGs, the optimum molecular weight for platelet PEGylation was between $2-5 \mathrm{kDa}$ [72].

In another study, Tarrand and Andersson [73] examined the effect of adding low molecular weight PEG (100-500 $\mathrm{g} / \mathrm{mol}$ ) to the preservation medium of platelets.

According to their patent study, PEG-treated platelets showed less platelet aggregation than the control group. Platelets in PEG medium could not bind to macrophages, indicating an increase in the duration of platelet circulation in the blood. In an in vivo study in a thrombocytopenic mouse model, it was shown that incubating platelets in a PEG-containing medium could prolong platelet function in mice, so that the platelets remained active until 11-12 days [73].

In addition, Maurer et al. [74] prepared PEGylated platelets that could be stored in good quality at sub-zero temperatures.

Because platelets are typically stored at $22-24^{\circ} \mathrm{C}$, Platelet products are decent places for bacteria to grow. Bacterial growth in platelet bags increases platelet aggregation and poses a risk to blood transfusions [75].

In this regard, Greco et al. [76] attempted to prevent bacteria-platelet interactions in platelet bags. They revealed that PEGylation of platelets significantly reduced the binding of Staphylococcus epidermidis bacteria to platelet concentrates.

In addition, PEGylation has been used to reduce the toxicity of other nanopolymers on platelets. As mentioned earlier, Liu et al. [50] used PEGylation of cationic PAMAM dendrimers to reduce platelet aggregation and the adverse effects of PAMAM on other blood components. Based on their results, PEGylation of the PAMAM dendrimer significantly reduced platelet aggregation.

In addition, Alavi et al. [51] examined the blood compatibility of G4 PAMAM dendrimers before and after binding to PEG. They showed that modifying the surface of PAMAM dendrimers with PEG reduced hemolysis and aggregation of RBCs and platelets and increased their blood compatibility.

In another study, Kim et al. [77] determined the effect of PEGylation of the ADP receptor antagonist PAMAM complex (PAMAM-PEG-CGS21680) on platelet aggregation. Based on this study, PAMAM-PEG-CGS21680 could inhibit ADP-mediated platelet aggregation depending on the number of PEGylated branches and different molecular weights of PEG.

Fuentes et al. [78] synthesized PEGylated lipid NPs with different surface charges and evaluated their effects on platelets. The cationic PEGylated lipid NPs inhibited ADPand collagen-induced platelet aggregation more than anionic lipid NPs. However, anionic lipid NPs inhibited aggregation more than neutral NPs did. These effects were concentration-dependent and could decrease P-selectin expression.

The effect of PEGylation of liposome-encapsulated hemoglobins (LEHs) on their thrombocytopenic reactions was investigated in two different studies $[79,80]$. Srinivasan et 
al. [79] suggested that PEGylation could reduce thrombocytopenic reactions mediated by LEHs in rabbits, while Wakamoto et al. [80] reported that PEGylation of LEHs could not change collagen, thrombin, and ristocetin-induced platelet aggregation.

The impacts of different sizes and concentrations of PEGylated PLGA NPs on platelets were determined by Bakhaidar et al. [81]. All PEGylated PLGA NPs in their study could bind and internalize onto platelets; however, they did not induce platelet aggregation and could not alter thrombin-induced platelet aggregation.

In addition, in another study [82], which determined the effects of various sizes of PLGA-PEG NPs on PRP, they also revealed that $113 \mathrm{~nm}$ PLGA-PEG NPs did not affect ADP-mediated platelet aggregation, while 321 and $585 \mathrm{~nm}$ NPs inhibited ADP-induced platelet aggregation at concentrations above $0.25 \mathrm{mg} / \mathrm{mL}$. In total, they reported that PEGylated PLGA NPs were platelet compatible. The details are listed in Table 1.

\section{Liposomes}

Liposomes are the first FDA-approved carriers for anticancer drugs because of their biodegradability, biocompatibility, non-toxicity, and amphiphilicity. Structurally, they are spherical and consist of two lipid layers [83-85]. Their properties vary based on the lipid composition, size, charge, and synthetic methods.

Zhang et al. [86] loaded ticagrelor (as a platelet inhibitor) into a synthetic liposome bearing the tumor-homing pentapeptide CREKA (Cys-Arg-Glu-Lys-Ala) and evaluated its inhibitory effects on activated platelets on the surface of metastatic cancer cells. Based on these results, the synthetic liposomes could selectively inhibit cancer cell-related platelets.

Okamura et al. [87] prepared a liposome by adding fibrinogen dodecapeptide (HHLGGAKQAGDV, H12) to encapsulate ADP (H12-(ADP)-vesicles) and evaluated their effect on hemostasis. They reported that H12-(ADP)-vesicles induced platelet aggregation through ADP release. In addition, they also showed that a decrease in lamellarity and an increase in membrane flexibility could enhance ADP release.

To design highly selective thrombolytic agents, Srinivasan et al. [88] and Vaidya et al. [89] applied arginylglycylaspartic acid (RGD)-modified liposomes and streptokinase, respectively, to synthesize NPs that can selectively target activated platelets. Both RGD-modified liposomes and streptokinase-encapsulated liposomes selectively target activated platelets $[88,89]$.

Kuznetsova et al. [90] investigated the blood compatibility of liposomes composed of neutral lipids loaded with methotrexate and melphalan decorated with or without a tetrasaccharide ligand. Based on their study, MTX-DOG had a larger size and more negative charge compared to Mlph-DOG. They showed that only MTX-DOG induced platelet aggregation, complement activation, and abnormal coagulation in a concentration-dependent manner.

To improve the coagulability of platelets, Chan [91] encapsulated thrombin into liposomes, which could be endocytosed by platelets ex vivo. These platelets were more sensitive to agonists and could improve clotting time, even under conditions in which platelets should have dysfunction and impaired coagulation. Table 1 presents the detailed results. Based on this table, anionic dendrimers with smaller sizes and low concentrations along with PEGylation can increase the stability and survival of platelets during storage.

\section{DISCUSSION}

In this study, the reported effects of polymeric nanoparticles on platelets between 2010 and 2020 were reviewed. The results of studies have shown that platelet membrane charge is negative; therefore, nanoparticles with positive charge facilitate platelet-platelet reactions by neutralizing the repulsive force between the negatively charged surfaces of cells and creating cross bridges among them, which causes platelet aggregation [40, 46, 68, 92]. Prevention of platelet aggregation during storage depends on other factors, such as size, shape, molecular weight, hydrophobicity, and concentration of nanoparticles. Therefore, nanoparticles with more surface negative charge, smaller size, lower molecular weight, at lower concentrations, and hydrophobic nature can be more effective in preventing platelet aggregation in platelet concentrates during storage $[40,44,46,48]$. The size and charge of nanoparticles play an important role in increasing platelet survival. For example, dendrimer nanoparticles with smaller sizes and negative charges prevent platelet aggregation and improve platelet function in platelet products, while large cationic dendrimers usually induce platelet aggregation through the electrostatic interaction of their highly positively charged surface and the negative points (e.g., acid sialic) on the surface of cells [46]. Therefore, it seems that surface modification of nanoparticles with nanoPEGylation can significantly increase platelet survival by inhibiting NP-induced platelet aggregation in platelet products [50, 77-82]. In addition, PEGylation of platelets can improve platelet quality during storage [72-74]. As mentioned earlier, cooling platelets during storage time induces PSLs in them, which results in altered morphology, aggregation, granule release, survival, and the expression of surface markers in cold-stored platelets, while storage of platelets at $22-24^{\circ} \mathrm{C}$ protects platelets from these lesions [72]. However, this temperature increases the possibility of bacterial growth in platelet products, which reduces the safety of blood transfusions [72, 74, 75]. In addition, $\alpha$ subunits of glycoprotein Ib (GPIb $\alpha)$ on the surface of platelets can irreversibly change during cold storage, resulting in rapid clearance of cold-stored donor platelets by macrophages [72]. On the other hand, PEGylation of platelets has been able to prevent the formation of PSTs in cold-stored platelets. PEGylated platelets have normal function and shape, and they significantly decrease microaggregation in cold-stored platelets (stored at $4^{\circ} \mathrm{C}$ and $-80^{\circ} \mathrm{C}$ ) [72-74]. The effectiveness of PEGylation in preserving platelets reduces the disposal of blood products. The storage of platelets at cold temperatures can also decrease microbial growth and enhance blood 
transfusion safety. Moreover, PEGylated platelets cannot be rapidly cleared from the bloodstream by macrophages [73]. In addition, PEGylation of blood cells depends on PEG size. While larger polymers $(20 \mathrm{kD})$ can be useful for PEGylation of RBCs and WBCs, a shorter polymer is better for platelets $(2-5 \mathrm{kD})$ [72]. Furthermore, although liposomes have been widely used to improve the storage conditions of erythrocytes, there is a paucity of information on the effects of these nanoparticles on platelet storage [93-97].

\section{CONCLUSION}

Based on the data collected from 2010 to 2020, we concluded that the presence of dendrimer nanoparticles with smaller size and negative charge, with low molecular weight and low concentration along with PEGylation, can increase the stability and survival of platelets during storage. In addition, PEGylation of platelets is a promising approach to improve the quality of platelet bags during storage.

\section{Authors' Disclosures of Potential Conflicts of Interest}

No potential conflicts of interest relevant to this article were reported.

\section{REFERENCES}

1. Foster TE, Puskas BL, Mandelbaum BR, Gerhardt MB, Rodeo SA. Platelet-rich plasma: from basic science to clinical applications. Am J Sports Med 2009;37:2259-72.

2. Árnason NA, Sigurjónsson OE. New strategies to understand platelet storage lesion. ISBT Sci Ser 2017;12:496-500.

3. Stohlawetz P, Horvath M, Pernerstorfer T, et al. Effects of nitric oxide on platelet activation during plateletpheresis and in vivo tracking of biotinylated platelets in humans. Transfusion 1999;39:506-14.

4. Shrivastava M. The platelet storage lesion. Transfus Apher Sci 2009;41:105-13.

5. Verma A, Agarwal P. Platelet utilization in the developing world: strategies to optimize platelet transfusion practices. Transfus Apher Sci 2009;41:145-9.

6. Dobrovolskaia MA, McNeil SE. Handbook of immunological properties of engineered nanomaterials. Volume 2: haematocompatibility of engineered nanomaterials. Singapore: World Scientific, 2016:261-302.

7. Fröhlich E. Action of nanoparticles on platelet activation and plasmatic coagulation. Curr Med Chem 2016;23:408-30.

8. Cicha I. Thrombosis: novel nanomedical concepts of diagnosis and treatment. World J Cardiol 2015;7:434-41.

9. Wang L, You X, Dai C, Tong T, Wu J. Hemostatic nanotechnologies for external and internal hemorrhage management. Biomater Sci 2020;8:4396-412.

10. Zielińska A, Carreiró F, Oliveira AM, et al. Polymeric nanoparticles: production, characterization, toxicology and ecotoxicology.
Molecules 2020;25:3731.

11. Braddock M. Nanomedicines: design, delivery and detection. London, UK: Royal Society of Chemistry, 2016.

12. Chambers P, McCarthy HO, Dunne NJ. Emerging areas of bone repair materials: nucleic acid therapy and drug delivery. In: Pawelec KM, Planell JA, eds. Bone repair biomaterials. 2nd ed. Cambridge, UK: Woodhead Publishing, 2019:411-46.

13. Fortunati E, Luzi F, Yang W, Kenny J, Torre L, Puglia D. Bio-based nanocomposites in food packaging. In: Cerqueira MAPR, Lagaron JM, Pastrana Castro LM, de Oliveira Soares Vicente AAM, eds. Nanomaterials for food packaging. Philadelphia, PA: Elsevier Inc, 2018:71-110.

14. Zadeh Mehrizi T, Mosaffa N, Haji Molla Hoseini M, et al. In vivo therapeutic effects of four synthesized antileishmanial nanodrugs in the treatment of Leishmaniasis. Arch Clin Infect Dis 2018; 13:e80314.

15. Zadeh Mehrizi T, Pirali Hamedani M, Ebrahimi Shahmabadi H, et al. Effective materials of medicinal plants for leishmania treatment in vivo environment. J Med Plants 2020;19:39-62.

16. Zadeh Mehrizi T, Shafiee Ardestani M, Haji Molla Hoseini M, Khamesipour A, Mosaffa N, Ramezani A. Novel nanosized chitosan-betulinic acid against resistant leishmania major and first clinical observation of such parasite in kidney. Sci Rep 2018;8:11759.

17. Mehrizi TZ, Ardestani MS, Molla Hoseini MH, Khamesipour A, Mosaffa N, Ramezani A. Novel nano-sized chitosan amphotericin B formulation with considerable improvement against Leishmania major. Nanomedicine (Lond) 2018;13:3129-47.

18. Wang YW, Liu CC, Cherng JH, et al. Biological effects of chitosan-based dressing on hemostasis mechanism. Polymers (Basel) 2019;11:1906.

19. Chan LW, Kim CH, Wang X, Pun SH, White NJ, Kim TH. PolySTAT-modified chitosan gauzes for improved hemostasis in external hemorrhage. Acta Biomater 2016;31:178-85.

20. Hu Z, Zhang DY, Lu ST, Li PW, Li SD. Chitosan-based composite materials for prospective hemostatic applications. Mar Drugs 2018; 16:273.

21. Liu H, Wang C, Li C, et al. A functional chitosan-based hydrogel as a wound dressing and drug delivery system in the treatment of wound healing. RSC Adv 2018;8:7533-49.

22. Pourshahrestani S, Zeimaran E, Adib Kadri N, et al. Galliumcontaining mesoporous bioactive glass with potent hemostatic activity and antibacterial efficacy. J Mater Chem B 2016;4:71-86.

23. Shi X, Fang Q Ding M, et al. Microspheres of carboxymethyl chitosan, sodium alginate and collagen for a novel hemostatic in vitro study. J Biomater Appl 2016;30:1092-102.

24. Gu R, Sun W, Zhou H, et al. The performance of a fly-larva shell-derived chitosan sponge as an absorbable surgical hemostatic agent. Biomaterials 2010;31:1270-7.

25. He Q Gong K, Ao Q, et al. Positive charge of chitosan retards blood coagulation on chitosan films. J Biomater Appl 2013;27:1032-45.

26. Lord MS, Cheng B, McCarthy SJ, Jung M, Whitelock JM. The modulation of platelet adhesion and activation by chitosan through plasma and extracellular matrix proteins. Biomaterials 2011;32:6655-62.

27. Chung TW, Lin PY, Wang SS, Chen YF. Adenosine diphosphatedecorated chitosan nanoparticles shorten blood clotting times, 
influencing the structures and varying the mechanical properties of the clots. Int J Nanomedicine 2014;9:1655-64.

28. Periayah MH, Halim AS, Hussein AR, Saad AZ, Rashid AH, Noorsal K. In vitro capacity of different grades of chitosan derivatives to induce platelet adhesion and aggregation. Int J Biol Macromol 2013;52:244-9.

29. Jesus S, Marques AP, Duarte A, et al. Chitosan nanoparticles: shedding light on immunotoxicity and hemocompatibility. Front Bioeng Biotechnol 2020;8:100.

30. Gopalakrishnan L, Ramana LN, Sethuraman S, Krishnan UM. Ellagic acid encapsulated chitosan nanoparticles as anti-hemorrhagic agent. Carbohydr Polym 2014;111:215-21.

31. Ramtoola Z, Lyons P, Keohane K, Kerrigan SW, Kirby BP, Kelly JG. Investigation of the interaction of biodegradable micro- and nanoparticulate drug delivery systems with platelets. J Pharm Pharmacol 2011;63:26-32.

32. Shelma R, Sharma CP. Development of lauroyl sulfated chitosan for enhancing hemocompatibility of chitosan. Colloids Surf B Biointerfaces 2011;84:561-70.

33. Xiong WY, Yi Y, Liu HZ, Wang H, Liu JH, Ying GQ. Selective carboxypropionylation of chitosan: synthesis, characterization, blood compatibility, and degradation. Carbohydr Res 2011;346: 1217-23.

34. Jiang G, Lin Z, Xu X, Zhang H, Song K. Stable nanomicelles based on chitosan derivative: in vitro antiplatelet aggregation and adhesion properties. Carbohydrate Polymers 2012;88:232-8.

35. Kim ES, Lee JS, Lee HG. Nanoencapsulation of red ginseng extracts using chitosan with polyglutamic acid or fucoidan for improving antithrombotic activities. J Agric Food Chem 2016;64:4765-71.

36. Abbasi E, Aval SF, Akbarzadeh A, et al. Dendrimers: synthesis, applications, and properties. Nanoscale Res Lett 2014;9:247.

37. Roeven E, Scheres L, Smulders MMJ, Zuilhof H. Design, synthesis, and characterization of fully zwitterionic, functionalized dendrimers. ACS Omega 2019;4:3000-11.

38. Zadeh Mehrizi T, Khamesipour A, Shafiee Ardestani M, et al. Comparative analysis between four model nanoformulations of amphotericin B-chitosan, amphotericin B-dendrimer, betulinic acid-chitosan and betulinic acid-dendrimer for treatment of Leishmania major: real-time PCR assay plus. Int J Nanomedicine 2019;14:7593-607.

39. Dobrovolskaia MA, Patri AK, Potter TM, Rodriguez JC, Hall JB, McNeil SE. Dendrimer-induced leukocyte procoagulant activity depends on particle size and surface charge. Nanomedicine (Lond) 2012;7:245-56.

40. Dobrovolskaia MA, Patri AK, Simak J, et al. Nanoparticle size and surface charge determine effects of PAMAM dendrimers on human platelets in vitro. Mol Pharm 2012;9:382-93.

41. Greish K, Thiagarajan G, Herd H, et al. Size and surface charge significantly influence the toxicity of silica and dendritic nanoparticles. Nanotoxicology 2012;6:713-23.

42. Jones CF, Campbell RA, Brooks AE, et al. Cationic PAMAM dendrimers aggressively initiate blood clot formation. ACS Nano 2012;6:9900-10.

43. Jones CF, Campbell RA, Franks Z, et al. Cationic PAMAM dendrimers disrupt key platelet functions. Mol Pharm 2012;9: 1599-611.

44. Chitlur M, Ware E, Kannan S, et al. Influence of nanopolymers with different end-functionalities on platelet function and the coagulation cascade - an ex-vivo study. Blood (ASH Annual Meeting Abstracts) 2006;108(Suppl):4038.

45. Šemberová J. Nanotechnology in the intensive care: intravascular biocompatibility of carbon nanomaterials-effect of carbon nanotubes on blood platelets [PhD dissertation]. Prague, Czech Republic: Charles University; 2012.

46. Aisina R, Mukhametova L, Ivanova E. Influence cationic and anionic PAMAM dendrimers of low generation on selected hemostatic parameters in vitro. Mater Sci Eng C Mater Biol Appl 2020;109:110605.

47. Enciso AE, Neun B, Rodriguez J, Ranjan AP, Dobrovolskaia MA, Simanek EE. Nanoparticle effects on human platelets in vitro: a comparison between PAMAM and triazine dendrimers. Molecules 2016;21:428.

48. Watala C, Karolczak K, Kassassir H, et al. How do the full-generation poly(amido)amine (PAMAM) dendrimers activate blood platelets? Activation of circulating platelets and formation of "fibrinogen aggregates" in the presence of polycations. Int J Pharm 2016;503:247-61.

49. Fu Y, Hu R, Li C, Wang Q, Liu Z, Xue W. Effects of poly (amidoamine) dendrimers on the structure and function of key blood components. J Bioact Compat Polym 2014;29:165-79.

50. Liu Y, Pang Y, Toh MR, Chiu GN. Dual-functionalized poly (amidoamine) dendrimers with poly(ethylene glycol) conjugation and thiolation improved blood compatibility. J Pharm Pharmacol 2015;67:1492-502.

51. Alavi SE, Muflih Al Harthi S, Ebrahimi Shahmabadi H, Akbarzadeh A. Cisplatin-loaded polybutylcyanoacrylate nanoparticles with improved properties as an anticancer agent. Int J Mol Sci 2019;20:1531.

52. Li P, Zheng W, Ma W, et al. In-situ preparation of aminoterminated dendrimers on $\mathrm{TiO} 2$ films by generational growth for potential and efficient surface functionalization. Appl Surf Sci 2018;459:438-45.

53. Ilinskaya AN, Dobrovolskaia MA. Nanoparticles and the blood coagulation system. Part I: benefits of nanotechnology. Nanomedicine (Lond) 2013;8:773-84.

54. Kim Y, Hechler B, Klutz AM, Gachet C, Jacobson KA. Toward multivalent signaling across $\mathrm{G}$ protein-coupled receptors from poly(amidoamine) dendrimers. Bioconjug Chem 2008;19:406-11.

55. de Castro S, Maruoka H, Hong K, et al. Functionalized congeners of P2Y1 receptor antagonists: 2-alkynyl (N)-methanocarba 2'-deoxyadenosine 3',5'-bisphosphate analogues and conjugation to a polyamidoamine (PAMAM) dendrimer carrier. Bioconjug Chem 2010;21:1190-205.

56. Ziemba B, Halets I, Shcharbin D, et al. Influence of fourth generation poly(propyleneimine) dendrimers on blood cells. J Biomed Mater Res A 2012;100:2870-80.

57. Ziemba B, Janaszewska A, Ciepluch K, et al. In vivo toxicity of poly (propyleneimine) dendrimers. J Biomed Mater Res A 2011; 99:261-8.

58. Franiak-Pietryga I, Ziolkowska E, Ziemba B, et al. Nanoparticlesa novel approach to chronic lymphocytic leukemia treatment? Blood (ASH Annual Meeting Abstracts) 2012;120(Suppl):4601.

59. Franiak-Pietryga I, Ziółkowska E, Ziemba B, et al. The influence of maltotriose-modified poly(propylene imine) dendrimers on 
the chronic lymphocytic leukemia cells in vitro: dense shell G4 PPI. Mol Pharm 2013;10:2490-501.

60. Peña-González CE, Pedziwiatr-Werbicka E, Shcharbin D, et al. Gold nanoparticles stabilized by cationic carbosilane dendrons: synthesis and biological properties. Dalton Trans 2017;46: 8736-45.

61. Pedziwiatr-Werbicka E, Peña-González CE, Stasiak K, et al. Toxicity of gold nanoparticles stabilized by cationic carbosilane dendrons. Minsk, Belarus: Belarusian State University, 2016.

62. Dzmitruk V, Pedziwiatr-Werbicka E, Shcharbin D, et al. Platelets aggregation induced by dendrimers and their complexes with siRNA and ODN, albumins impact on the process. News Biomed Sci 2015;12:139-43.

63. Barrios-Gumiel A, Sánchez-Nieves J, Pedziwiatr-Werbicka E, et al. Effect of PEGylation on the biological properties of cationic carbosilane dendronized gold nanoparticles. Int J Pharm 2020; 573:118867.

64. Hashempour Alamdari N, Alaei-Beirami M, Sadat Shandiz SA, et al. $\mathrm{Gd}^{3+}$-asparagine-anionic linear globular dendrimer secondgeneration G2 complexes: novel nanobiohybrid theranostics. Contrast Media Mol Imaging 2017;2017:3625729.

65. Mirzaei M, Mohagheghi M, Shahbazi-Gahrouei D, Khatami A. Novel nanosized $\mathrm{GD}^{3+}$-ALGD- $\mathrm{G}_{2}-\mathrm{C} 595$ : in vivo dual selective MUC-1 positive tumor molecular MR imaging and therapeutic agent. J Nanomed Nanotechnol 2012;3:1000147.

66. Mehrizi TZ, Ardestani MS, Khamesipour A, et al. Reduction toxicity of Amphotericin B through loading into a novel nanoformulation of anionic linear globular dendrimer for improve treatment of leishmania major. J Mater Sci Mater Med 2018;29:125.

67. Mirzaei H, Kazemi B, Bandehpour M, et al. Computational and nonglycosylated systems: a simpler approach for development of nanosized PEGylated proteins. Drug Des Devel Ther 2016; 10:1193-200.

68. Alavidjeh MS, Haririan I, Khorramizadeh MR, Ghane ZZ, Ardestani MS, Namazi H. Anionic linear-globular dendrimers: biocompatible hybrid materials with potential uses in nanomedicine. J Mater Sci Mater Med 2010;21:1121-33.

69. Fernandes EG, de Queiroz AA, Abraham GA, San Román J. Antithrombogenic properties of bioconjugate streptokinasepolyglycerol dendrimers. J Mater Sci Mater Med 2006;17:105-11.

70. D'souza AA, Shegokar R. Polyethylene glycol (PEG): a versatile polymer for pharmaceutical applications. Expert Opin Drug Deliv 2016;13:1257-75.

71. Knop K, Hoogenboom R, Fischer D, Schubert US. Poly(ethylene glycol) in drug delivery: pros and cons as well as potential alternatives. Angew Chem Int Ed Engl 2010;49:6288-308.

72. Scott MD, Nakane N, Maurer-Spurej E. Cryoprotection of platelets by grafted polymers. In: Quain M, ed. Cryopreservationcurrent advances and evaluations. London, UK: IntechOpen, 2019.

73. Tarrand J, Andersson B. Compositions and methods for prolonged cell storage. Austin, TX: The University of Texas System, 2018.

74. Maurer E, Scott MD, Kitamura N. Cold storage of pegylated platelets at about or below $0^{\circ}$ C. Ottawa, CA: Canadian Blood Services, 2011.

75. Kerrigan SW, Cox D. Platelet-bacterial interactions. Cell Mol Life
Sci 2010;67:513-23.

76. Greco CA, Maurer-Spurej E, Scott MD, Kalab M, Nakane N, Ramírez-Arcos SM. PEGylation prevents bacteria-induced platelet activation and biofilm formation in platelet concentrates. Vox Sang 2011;100:336-9.

77. Kim Y, Hechler B, Gao ZG, Gachet C, Jacobson KA. PEGylated dendritic unimolecular micelles as versatile carriers for ligands of G protein-coupled receptors. Bioconjug Chem 2009;20:1888-98.

78. Fuentes E, Yameen B, Bong SJ, Salvador-Morales C, Palomo I, Vilos C. Antiplatelet effect of differentially charged PEGylated lipid-polymer nanoparticles. Nanomedicine 2017;13:1089-94.

79. Srinivasan M, Sudheer AR, Pillai KR, Kumar PR, Sudhakaran PR, Menon VP. Modulatory effects of curcumin on $\gamma$-radiationinduced cellular damage in primary culture of isolated rat hepatocytes. Environ Toxicol Pharmacol 2007;24:98-105.

80. Wakamoto S, Fujihara M, Abe $\mathrm{H}$, et al. Effects of poly (ethyleneglycol)-modified hemoglobin vesicles on agonist-induced platelet aggregation and RANTES release in vitro. Artif Cells Blood Substit Immobil Biotechnol 2001;29:191-201.

81. Bakhaidar R, Green J, Alfahad K, et al. Effect of size and concentration of PLGA-PEG nanoparticles on activation and aggregation of washed human platelets. Pharmaceutics 2019;11:514.

82. Bakhaidar R, O'Neill S, Ramtoola Z. PLGA-PEG nanoparticles show minimal risks of interference with platelet function of human platelet-rich plasma. Int J Mol Sci 2020;21:9716.

83. Akbarzadeh A, Rezaei-Sadabady R, Davaran S, et al. Liposome: classification, preparation, and applications. Nanoscale Res Lett 2013;8:102.

84. Beltrán-Gracia E, López-Camacho A, Higuera-Ciapara I, VelázquezFernández JB, Vallejo-Cardona AA. Nanomedicine review: clinical developments in liposomal applications. Cancer Nano 2019;10:11.

85. Shahabi J, Shahmabadi HE, Alavi SE, et al. Effect of gold nanoparticles on properties of nanoliposomal hydroxyurea: an in vitro study. Indian J Clin Biochem 2014;29:315-20.

86. Zhang Y, Wei J, Liu S, et al. Inhibition of platelet function using liposomal nanoparticles blocks tumor metastasis. Theranostics 2017;7:1062-71.

87. Okamura Y, Katsuno S, Suzuki H, et al. Release abilities of adenosine diphosphate from phospholipid vesicles with different membrane properties and their hemostatic effects as a platelet substitute. J Control Release 2010;148:373-9.

88. Srinivasan R, Marchant RE, Gupta AS. In vitro and in vivo platelet targeting by cyclic RGD-modified liposomes. J Biomed Mater Res A 2010;93:1004-15.

89. Vaidya B, Nayak MK, Dash D, Agrawal GP, Vyas SP. Development and characterization of site specific target sensitive liposomes for the delivery of thrombolytic agents. Int J Pharm 2011;403:254-61.

90. Kuznetsova NR, Sevrin C, Lespineux D, et al. Hemocompatibility of liposomes loaded with lipophilic prodrugs of methotrexate and melphalan in the lipid bilayer. J Control Release 2012;160: 394-400.

91. Chan VWT. Liposomal-encapsulated enzymes can be delivered to and modify platelet function ex vivo [ $\mathrm{PhD}$ dissertation]. Vancouver, Canada: University of British Columbia, 2018.

92. Chen KY, Lin TH, Yang CY, Kuo YW, Lei U. Mechanics for the 
adhesion and aggregation of red blood cells on chitosan. J Mech 2018;34:725-32.

93. Stoll C, Holovati JL, Acker JP, Wolkers WF. Liposomes composed of unsaturated lipids for membrane modification of human erythrocytes. Mol Membr Biol 2011;28:454-61.

94. Da Silveira Cavalcante L. The effects of liposome treatment on red blood cells during hypothermic storage [PhD dissertation]. Edmonton, Canada: University of Alberta, 2017.
95. da Silveira Cavalcante L, Feng Q Chin-Yee I, Acker JP, Holovati JL. Effect of liposome-treated red blood cells in an anemic rat model. J Liposome Res 2017;27:56-63.

96. Stadnick H, Stoll C, Wolkers WF, Acker JP, Holovati JL. The effect of liposome treatment on the quality of hypothermically stored red blood cells. Biopreserv Biobank 2011;9:335-42.

97. Stadnick HPA. The deformability of hypothermically stored red blood cells. Edmonton, CA: University of Alberta, 2011. 